\title{
Impact of climatic parameters on simulated yield of rice at Faizabad of U.P.
}

\author{
ARVIND KUMAR, S. K. TRIPATHI ${ }^{1}$ and PADMAKAR TRIPATHI \\ N. D. University of Agriculture \& Technology, Faizabad-224 229, Uttar Pradesh \\ ${ }^{1}$ Department of Water Resources Development and Management, IIT Roorkee, Roorkee-247 667 \\ e-mail:arvindmausam@gmail.com
}

\begin{abstract}
Impact of climatic parameters on grain yield of rice cultivars under three dates of transplanting $\left(30^{\text {th }}\right.$ June, $15^{\text {th }}$ July and $30^{\text {th }}$ July) was assessed at Faizabad Uttar Pradesh using calibrated and validated CERES-Rice model by incremental change in climatic parameters. The increase in sunshine duration and solar radiation caused increase in the yield and vice versa, while increase in maximum and minimum temperatures caused decrease in the yield. Among the sowing dates, the impact of sunshine duration under early transplanted rice $\left(30^{\text {th }}\right.$ June) was higher than late transplanted rice $\left(30^{\text {th }}\right.$ July). While the reverse trend was observed in case of solar radiation. The effect of maximum and minimum temperatures under early transplanted rice was also higher than that of late transplanted rice.
\end{abstract}

Key words: DSSAT, photoperiod, rice, simulated yield and solar radiation.

Rice (Oryza sativa L.) is an essential food for more than two billion people. Two thirds of the world's population are living in Asia where rice is the prime source of daily food. In 2011, rice was grown on about 161.42 lakh ha in the entire world, out of which 126.90 lakh ha was in Asia. Worldwide, India stands first in rice area (444.06 lakh ha) and second in rice production (131.27 million tons) after China. It contributes 21.5 per cent of global rice production. Within the country, rice occupies one-quarter of the total cropped area, contributes about 40 to 43 per cent of total food grain production and continues to play a vital role in the national food and livelihood security system. India, the country having the largest rice area in the world has only $41 \%$ of the productivity reached in USA and $48 \%$ of that in China. India's annual rice production is around 85-90 million tones and annual consumption is around 85 million tones. Total food grains production of India during 2010-11 was 244.78 million tones whereas during 2011-12 it was 252.56 million tons in which, the rice production was 103.41 million tons (Anonymous, 2012). This makes the production of rice an important social, political and economic factor. India's target for rice production is 120-130 million tons by 2025 (Rai, 2006). Since there is no scope for area expansion, additional production has to come by increasing the productivity matching at least with the population growth. In the recent years there has been a growing concern about the changes in climatic condition for its negative impact on rice productivity in this state but this needed technical verification. Keeping these points in view the present study was undertaken.

\section{MATERIALS AND METHODS}

The DSSATV 4.5 (CERES-Rice) model was calibrated with the historical crop data available at university and validated with the two years (kharif 2011 \& 2012) rice crop data collected under the present investigation for three popular rice cultivars namely NDR-97 (short duration), NDR-359 (medium duration) and Swarna Sub-1 (long duration). The average weather condition of 1971-2012 was used to run the model and thus, the simulated yield obtained was called the base yield. Sunshine duration ( $\pm 0.5-1.0 \mathrm{hrs})$, solar radiation $\left( \pm 1.0-3.0 \mathrm{M} \mathrm{J} \mathrm{m}^{-2} \mathrm{day}^{-1}\right)$, maximum temperature $\left( \pm 0.5-1.5^{\circ} \mathrm{C}\right)$ and minimum temperature $\left( \pm 0.5-1.5^{\circ} \mathrm{C}\right)$ were modified and yields of rice cultivars were simulated under three dates of transplanting ( $30^{\text {th }} \mathrm{June}, 15^{\text {th }} \mathrm{July}$ and $30^{\text {th }}$ July).

\section{RESULTS AND DISCUSSION}

The impact of climatic parameters viz. sunshine duration, solar radiation, maximum and minimum temperatures on grain yield of rice as simulated by the model is presented in Figs. 1 to 4. Fig. 1 shows that with increase in sunshine duration there is increase in yield under all the dates of transplanted rice and vice versa. The rice yield increased upto $6.3-6.7 \%$ with increase in sunshine duration of $1.0 \mathrm{~h}$ under $30^{\text {th }}$ June to $15^{\text {th }}$ July transplanted rice and 


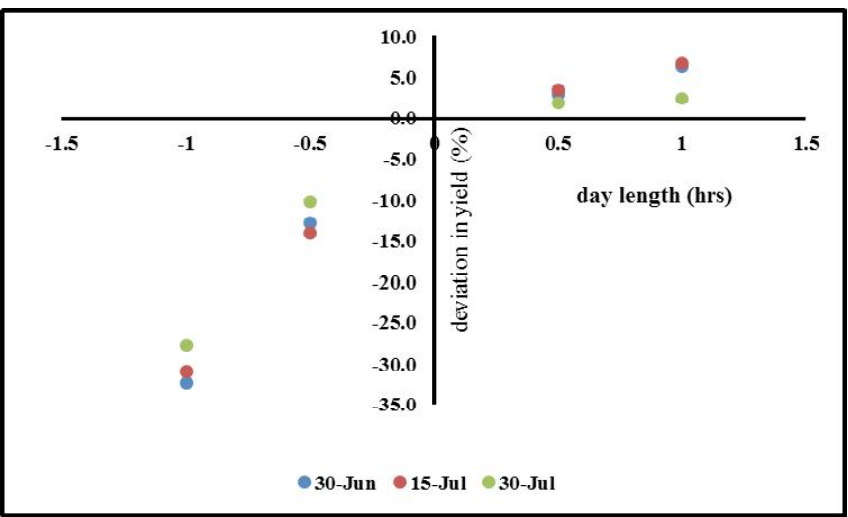

Fig. 1: Effect of day length on simulated yield of rice varieties

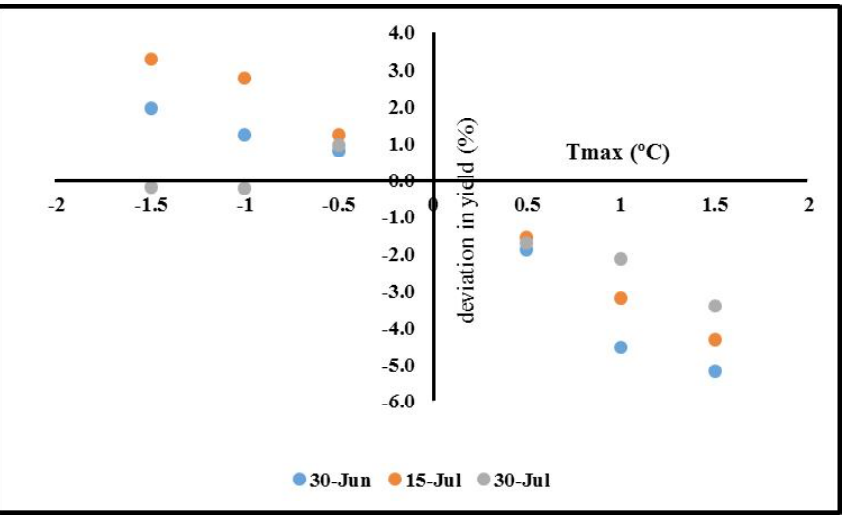

Fig. 3: Effect of maximum temperature on simulated yield of rice varieties

decreased upto $30-35 \%$ with decrease in sunshine duration (Fig. 1). Sastri et al., (1999) also reported similar findings in their study. The effect of increase or decrease in solar radiation by $1-3 \mathrm{M} \mathrm{J} \mathrm{m}^{-2} \mathrm{day}^{-1}$ (Fig. 2) indicates that there is a positive relationship between yield and solar radiation similar to that observed in case of sunshine duration. However, the magnitude of impact was less than that of sunshine duration. Moreover, the late transplanted rice is affected more than early transplanted rice crop due to solar radiation. The timely transplanting of rice crop is least impacted due to decrease of solar radiation. Linear relation between grain yield and solar radiation has also been reported by Islam and Morison (1992). An increase in maximum and minimum temperatures caused decrease in rice yield and decrease in temperatures caused increase in the yield (Fig. $3 \& 4$ ). The $30^{\text {th }}$ June transplanting of rice was identified as the suitable date in reference to the better grain yield. The similar results have been reported by Shamim et al., (2010) and Bemal et al., (2009).

\section{CONCLUSION}

The simulation study has proved that rice crop

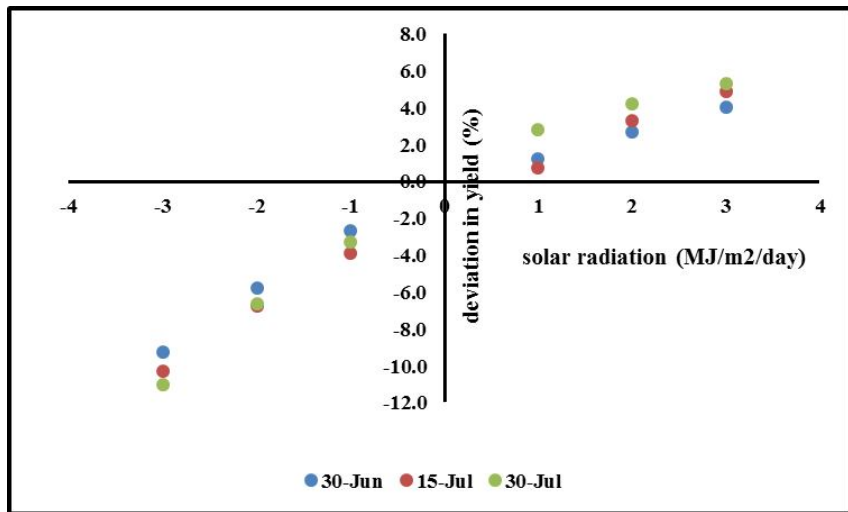

Fig. 2: Effect of solar radiation on simulated yield of rice varieties

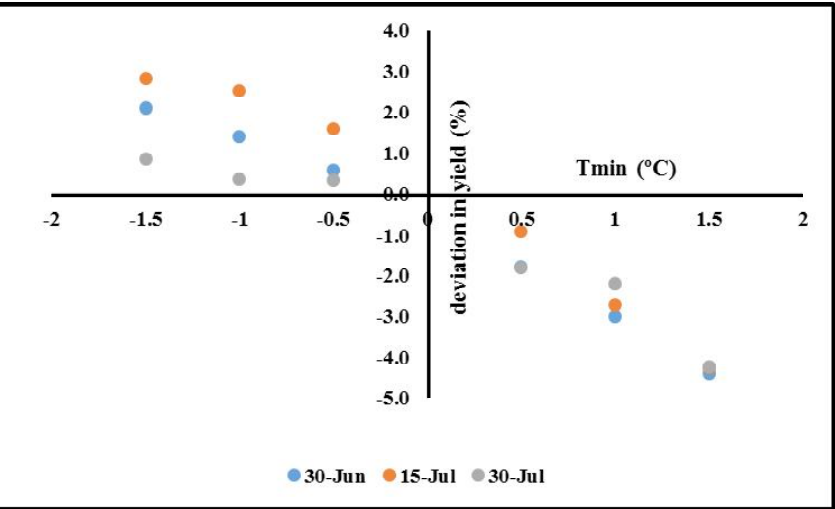

Fig. 4: Effect of minimum temperature on simulated yield of rice varieties

transplanted on $30^{\text {th }}$ June was found best under present investigation with respect to sunshine duration, solar radiation, maximum and minimum temperatures.

\section{ACKNOWLEDGEMENT}

Authors duly acknowledges the India Meteorological Department, Pune and Department of Agricultural Meteorology, NDUAT, Faizabad for providing meteorological and yield data.

\section{REFERENCES}

Anonymous (2012). Socio-economic review (2011-12), Directorate of Economics and Statistics, Govt. of India, New Delhi, p. 18.

Bemal, S., Singh, D. and Singh, S. (2009). Seasonal climatic variability impact on rice productivity in Haryana. $J$. Agrometeorol., 11(Special issue):64-66.

Islam, M. S. and Morison, J. I. L. (1992). Influence of solar radiation and temperature on irrigated rice grain yield in Bangladesh. Field Crop Res., 30(1-2):13-28. 
Rai, Mangala (2006). Rice Research. ICAR News-A science and Technology News letter, July-September, 2006, p. 20.

Sastri,A.S.R.A.S., Rai, S.K., Nidu, D. and Srivastava,A.K. (1999). Influence of climate parameters on productivity of rainfed rice-case study of Chattisgarh. In: "Rice-in a variable climate." (Eds. Y. P. Abroland SulochaneGadgil), pp. 5161, (APC Publications Pvt. Ltd., New Delhi, India).
Shamim, M., Shekh,A.M., Pandey, V., Patel, H.R. and Lunagaria, M.M. (2010). Sensitivity of CERES-Rice model to different environmental parameters on the productivity of aromatic rice in middle Gujarat. J. Agrometeorol., 12(2):213-216. 